\title{
A PERSPECTIVA DE PROFISSIONAIS DE SAÚDE SOBRE OS PARTOS DE NATIMORTOS
}

\author{
LA PERSPECTIVA DE LOS PROFESIONALES DE SALUD \\ SOBRE PARTOS DE NACIDOS MUERTOS
THE PERSPECTIVE OF HEALTHCARE PROFESSIONALS ON BIRTH OF STILLBORN

\author{
Jacqueline Isaac Machado Brigagão ${ }^{1}$, Roselane Gonçalves ${ }^{1}$ \\ e Bruna Martins Cardoso da Silva ${ }^{1}$
}

${ }^{1}$ Universidade de São Paulo, São Paulo/SP, Brasil

\begin{abstract}
RESUMO: Profissionais que atuam em hospitais/maternidades enfrentam muitos desafios no atendimento a mulheres que estão vivenciando óbitos fetais, isso porque o habitual nesses locais é lidar com nascimento e vida. Nesse contexto, o objetivo deste estudo foi compreender a perspectiva de profissionais de saúde sobre o parto e o pós-parto de mulheres com diagnóstico de óbito fetal. Trata-se de uma pesquisa qualitativa orientada pela perspectiva construcionista; foram realizadas entrevistas semidirigidas com profissionais que atuam em um hospital/maternidade do estado de São Paulo. A análise discursiva indicou que as/os profissionais de saúde se identificam com o luto das mulheres e das famílias, mas não conseguem se aproximar delas e oferecer intervenções terapêuticas para além da medicalização. Desse modo, é fundamental investir na formação profissional para lidar com a morte, nos cursos de graduação em saúde e nos de educação continuada, nas maternidades e casas de parto.
\end{abstract}

PALAVRAS-CHAVE: Luto; Natimorto; Profissionais de saúde; Parto; Práticas discursivas.

RESUMEN: Los profesionales que trabajan en hospitales / maternidades enfrentan muchos desafíos en el cuidado de mujeres que están sufriendo muerte fetal, porque lo que se acostumbra en estos lugares es lidiar con el nacimiento y la vida. En este contexto, el objetivo de este estudio fue comprender la perspectiva de los profesionales de la salud sobre el parto y el puerperio de las mujeres diagnosticadas de muerte fetal. Es una investigación cualitativa guiada por la perspectiva construccionista, se realizaron entrevistas semiestructuradas a profesionales que laboran en un hospital / maternidad del estado de São Paulo. El análisis discursivo indicó que los profesionales de la salud se identifican con el duelo de las mujeres y las familias, pero son incapaces de acercarse a ellas y ofrecer intervenciones terapéuticas más allá de la medicalización. Por ello, es fundamental invertir en formación profesional para afrontar la muerte, en cursos de pregrado en salud y en educación continua, en maternidades y centros de nacimientos.

PALABRAS CLAVE: Duelo; Nacido muerto; Profesionales de la salud; Parto; Prácticas discursivas.

ABSTRACT: Professionals working in maternity hospitals face many challenges in the care of women who are experiencing fetal deaths, because the usual in these places is to deal with birth and life. In this context, the aim of this study was to understand the perspective of health professionals about the labor and postpartum of the women diagnosed with fetal death. This is a qualitative research guided by the constructionist perspective; semidirected interviews were conducted with professionals working in a maternity hospital in the state of São Paulo. The discursive analysis indicated that health professionals understand the mourning of the women and families, but cannot approach them and offer therapeutic interventions beyond medicalization. This way, it is essential to invest in training actions to deal with death, in undergraduate health courses and in those of continuing education in maternity hospitals and birth centers.

KEYWORDS: Mourning; Stillbirth; Health professionals; Childbirth, Discursive practices. 


\section{Introdução}

Os casos de óbitos fetais intrauterinos (OFIU) impõem muitos desafios para as/os profissionais que atuam em maternidades, nas quais o habitual é lidar com nascimento e vida. Os modos de lidar com a morte são construídos na interface entre cultura, técnicas, práticas e valores. Quando se trata de morte de crianças, Pancino e Silveria (2010) afirmam que na antiguidade os índices de mortalidade infantil eram muito altos e a morte de crianças era vista como um fato normal/corriqueiro; mas essas mortes, muitas vezes, eram vivenciadas como uma desventura. Essa noção da morte de crianças e bebês como tragédia foi incrementada com o advento da modernidade e todas as construções sociais da criança como inocente, frágil, carente de proteção (Ariès, 1981). Ademais, muitas tecnologias biomédicas foram desenvolvidas - como exames que apresentam o feto por meio de imagens cada vez mais nítidas e detalhadas e métodos de diagnósticos e tratamentos diversos -, enquanto a taxa de mortalidade infantil apresentou diminuição significativa.

No Brasil são consideradas OFIU as mortes de fetos acima de 22 semanas, momento em que, na maioria das vezes, as mulheres e famílias já criaram vínculos e expectativas em relação a esses bebês, e a notícia da morte as deixa tristes e profundamente abaladas durante o trabalho de parto/parto e todo o período pós-parto. De acordo com Lawn et al. (2016), estima-se que em 2015, no mundo, ocorreram cerca de 2.6 milhões de óbitos fetais. O número de natimortos diminuiu mais lentamente do que a mortalidade materna ou a mortalidade das crianças com menos de 5 anos, que foram explicitamente incluídas nas metas dos Objetivos de Desenvolvimento do Milênio. Em 2016, no sumário executivo da segunda série especial sobre óbitos fetais, a revista The Lancet recomendou o aprimoramento nas interações entre familiares e profissionais de saúde que atuam na linha de frente, devendo os cuidados imediatos com o luto ser respeitosos e fazer parte da rotina de trabalho de todos/as as/os profissionais de saúde. Homer e Hoope-Bender (2016) destacam que são as/os profissionais de saúde os que podem oferecer apoio social e emocional à família antes, durante e após o nascimento e facilitar os processos de elaboração do luto. Barbeiro et al. (2015) destacam a importância de investimento em pesquisas sobre óbito fetal no Brasil.

Os estudos sobre as percepções dos profissionais de saúde sobre as mortes perinatais indicam que eles enfrentam muitas dificuldades ao lidar com essa situação nos diferentes momentos da hospitalização. O momento de comunicar o diagnóstico do óbito do bebê aos pais é percebido como desconfortável e marcado por intensa ansiedade quanto ao melhor modo de dar essa notícia (Lemos \& Cunha, 2015). Nesse sentido, Amthauer (2017) e Barlem et al. (2014) discutem que a comunicação dos óbitos a familiares e seus pares é vivenciada pelos profissionais de saúde como uma tarefa complexa e difícil, sendo a estratégia mais utilizada a adoção de uma postura técnica, de distanciamento do sofrimento do outro. Kingdon, O’Donnell, Givens e Turner (2015), em uma metassíntese dos estudos qualitativos sobre o papel dos profissionais de saúde no encorajamento aos familiares de natimortos para que vejam e segurem no colo os seus bebês, concluem que, apesar de na literatura não haver um consenso sobre os benefícios desse contato, as/os profissionais de saúde têm um papel fundamental nesse processo e devem auxiliar os pais a tomarem decisões apropriadas nessa situação. Nesse contexto, Hochberg (2011) aponta que uma das questões que precisam ser discutidas com as mulheres e seus familiares é a possibilidade de fotografar o bebê. Isso porque, uma vez que após o nascimento permanecem com ele por um curto intervalo de tempo, as fotografias podem auxiliar no processo de construção de memórias e narrativas sobre essa 
história.

Os estudos sobre os cuidados prestados aos casos de óbito fetal também destacam a importância de os serviços/hospitais prepararem o ambiente físico para os partos de natimortos com áreas privativas destinadas a essas famílias. A maioria dos hospitais não foi originalmente projetada para realizar esses atendimentos, e muitas vezes eles ocorrem em espaços improvisados, que não possibilitam às famílias sentirem-se acolhidas. Além disso, é essencial desenvolver ações de cuidado culturalmente sensíveis e possibilitar espaços para que as mulheres e as suas famílias possam realizar os rituais de despedida (Kelley \& Trinidad, 2012).

Ellis et al. (2016), numa revisão sistemática de estudos qualitativos e quantitativos sobre os atendimentos hospitalares nos casos de óbito fetal, observam que muitas/os profissionais de saúde apontam a falta de treinamento como uma das principais barreiras para a realização do trabalho; e reconhecem que uma das estratégias para amenizar o seu sofrimento nesses casos é concentrarem-se nas atividades operacionais, assumindo um distanciamento da mulher e seus familiares. Montero et al. (2011), estudando as percepções de profissionais de saúde sobre as perdas perinatais, concluem que a ausência de discussões sobre essas questões na formação profissional faz com que, no cotidiano, as atitudes sejam inadequadas e provoquem sensações de desamparo, ansiedade e frustração, as quais afetam o sentimento de competência profissional. Nesse sentido, Lima e Andrade (2017) destacam que os modos compartimentados de organização tradicional dos currículos em saúde são incoerentes com as demandas do trabalho, que exigem um olhar humanizado, ético e responsável.

A necessidade de ampliar a formação dos profissionais de saúde para lidar com a morte é um consenso na literatura, bem como a importância de investir na reformulação dos currículos de graduação e propor uma educação para a morte nos cursos de saúde (Bandeira \& Bisogno, 2011; Hermes \& Lamarca, 2013; Kovács, 2016; Lima \& Andrade, 2017; Praxedes, Araújo, \& Nascimento, 2018). Em relação aos óbitos fetais, esses estudos indicam que um atendimento de qualidade no hospital tem efeitos de longo prazo na saúde mental das mulheres e famílias nos processos de elaboração dessa perda. Nesse sentido, concluem que os profissionais que atuam no campo da obstetrícia devem ser treinados para lidar com o luto perinatal (Keley \& Trinidad, 2012; Subtzki, Lomba, \& Backes, 2018).

A discussão sobre a dimensão social do luto tem sido abordada por Butler (2004, 2016) nas discussões sobre vida precária. A autora realiza uma leitura das teorias de Freud sobre o luto e afirma que quando nos defrontamos com a morte ocorre uma profunda transformação que afeta todos os que a vivenciam. No fim do processo, o objeto de amor permanece no psiquismo, não mais investido de dor e tristeza, mas como parte de nossa história. Ela enfatiza que não há autonomia ou escolha nos processos de luto; somos tomados pela dor e inevitavelmente temos de lidar com ela. O luto nos leva a retomar a perspectiva de que a vida é precária e de que não temos o controle e a autonomia que a sociedade capitalista e liberal quer nos fazer acreditar que são constitutivos dos seres humanos.

Butler (2004) também observa que o luto não é somente algo do universo privado. Para a autora, ele presentifica as relações de interdependência entre as pessoas e possibilita a construção de um sentimento de coletividade e de pertencimento a uma comunidade política:

Muitas pessoas pensam que o luto é privado, que nos leva a uma situação solitária e, nesse sentido, é despolitizado. Mas acho que esse fornece um senso de comunidade política de uma ordem complexa, e faz isso, em primeiro lugar, trazendo à 
tona os laços relacionais que têm implicações para teorizar a dependência fundamental e a responsabilidade ética. Se o meu destino não é originalmente ou finalmente separável do seu, então o "nós" é atravessado por uma relacionalidade que não podemos facilmente argumentar contra; ou, melhor, podemos argumentar contra isso, mas estaríamos negando algo fundamental sobre as condições sociais de nossa própria formação. (Butler, 2004, pp. 22-23; tradução nossa)

Assim, a despeito de todas as diferenças sociais, econômicas e culturais entre as pessoas, há um sentimento que todos conhecem e com o qual se identificam: a vulnerabilidade diante da morte. Trata-se do reconhecimento da nossa finitude e da possibilidade de perder alguém, e é essa identificação com a condição de fragilidade que possibilita o surgimento de um "nós" (Butler, 2004).

Nesse sentido, para as/os profissionais de saúde a perda de um bebê parece ser uma morte digna de luto que lhes afeta diretamente; porém, a mobilização afetiva que sentem prejudica a qualidade do atendimento oferecido às mulheres e suas familias. Assim, o objetivo desta pesquisa foi compreender a perspectiva de profissionais de saúde sobre o parto e o pós-parto de mulheres com diagnóstico de óbito fetal

\section{Metodologia}

Trata-se de uma pesquisa qualitativa orientada pela perspectiva construcionista, o que significa dizer que entendemos a linguagem como um modo de agir no mundo, buscando, assim, romper com as vertentes representacionistas do conhecimento (Mello, Silva, Lima \& Di Paolo, 2007; Spink \& Medrado, 1999). A estratégia de investigação que utilizamos foi a das entrevistas semidirigidas, que possibilitaram a interação entre as pesquisadoras e os/as colaboradores da pesquisa, a explicitação de diferentes posicionamentos, a circulação de repertórios sobre os temas discutidos e a produção de sentidos compartilhados entre as/os interlocutoras/es (Aragaki, Lima, Pereira, \& Nascimento, 2014). Nesse contexto, os repertórios interpretativos são entendidos como o agrupamento de termos, descrições, lugares comuns e figuras de linguagem, reunidos em torno de metáforas ou imagens, utilizados na linguagem cotidiana. São produzidos pela comunidade linguística e são transmitidos nos processos de socialização e nas relações que estabelecemos ao longo do tempo (Potter \& Wetherell, 1987).

Entrevistamos profissionais que atuavam num hospital/maternidade do estado de São Paulo. O único critério de inclusão era estar no rol das/os profissionais que atendiam mulheres com diagnóstico de óbito fetal e suas famílias. Participaram da pesquisa dez profissionais: uma médica obstetra e uma enfermeira obstétrica, quatro auxiliares de enfermagem, um enfermeiro que trabalhava na clínica médica, duas psicólogas e uma assistente social.

As entrevistas semidirigidas foram realizadas em espaços privados dentro do hospital a fim de garantir a privacidade e tranquilidade das/dos participantes. A participação foi sempre voluntária e todas/os as/os profissionais assinaram o Termo de Consentimento Livre e Esclarecido (TCLE), bem como autorizaram a gravação em áudio. O estudo foi aprovado por Comitê de Ética em Pesquisa. Apesar de haver um roteiro norteador, as entrevistas transcorreram como conversa e em um clima de intimidade. Apresentamonos como pesquisadoras, mas, provavelmente porque as/os participantes sabiam que 
atuávamos no campo da obstetrícia, na maioria dos diálogos elas/es nos posicionaram como colegas de trabalho e conhecedoras dos jargões linguísticos da área e dos desafios desse campo. Esse jogo de posicionamentos facilitou as conversas e possibilitou o compartilhamento e a coconstrução dos sentidos de óbito fetal.

Todas as entrevistas foram transcritas e submetidas à análise discursiva. No processo analítico priorizamos os repertórios interpretativos utilizados pelas/os profissionais. Iniciamos a análise com a leitura livre da transcrição de cada entrevista e a identificação das principais temáticas presentes em cada discurso. Em seguida, buscamos identificar as temáticas que apareciam de modo transversal nos discursos das/dos entrevistadas/os, o que possibilitou apontar dois principais repertórios interpretativos: o dos desafios e sofrimento e a da formação para cuidar de partos de natimortos.

Vale ressaltar que, de acordo com Spink (2010), sempre que falamos acerca de um tema muitas outras vozes e repertórios do presente e do passado se presentificam. Isso porque a cultura e o imaginário social catalisam os repertórios do tempo longo, que são atualizados nas conversações do presente. A seguir, trazemos os principais temas presentes nos discursos das/os profissionais de saúde sobre os OFIU.

\section{Resultados}

\section{O sofrimento e os desafios que as/os profissionais de saúde enfrentam no acompanhamento de partos de natimortos}

Nesse repertório as/os profissionais se posicionaram como sofrendo muito diante do óbito fetal, associando-o aos desafios que têm de enfrentar para realizar o atendimento de mulheres com diagnóstico de OFIU. As expressões mais utilizadas para expressar o sofrimento foram: "é muito triste"; "é um momento tenso para toda a equipe"; "é uma situação dramática"; "é horrível você tirar um bebê morto"; "ninguém tá satisfeito"; "é o fracasso".

O relato abaixo exemplifica como o sofrimento faz com que as/os profissionais busquem evitar a situação e se posicionem de modo a evitar atender a esses partos.

\section{Ninguém quer fazer. Fica todo mundo empurrando um para o outro. É horrível você tirar um bebê morto, é muito ruim. ... Quando eles já estão bem formados, é muito triste de você ver a mulher chorar, abraçar. É horrível, não é uma história que a gente gosta de contar. (Enfermeira obstétrica)}

Mello e Silva (2012), Hoffman (1993) e Lemos e Cunha (2015) observaram em seus estudos que o sofrimento das/os profissionais diante da morte de crianças é intenso, já que, para eles, trata-se da interrupção de um ciclo natural da vida. A leitura de que a morte de bebês é antinatural, é vida que não deveria ser interrompida foi compartilhada pelas participantes de nossa pesquisa. Porém, aliado ao sofrimento, as/os profissionais apontaram que precisam enfrentar também vários desafios nos diferentes momentos de atendimento a essas mulheres. As expressões mais associadas aos desafios foram: "é uma grande dificuldade"; "a gente enfrenta”; "é difícil”; "a gente não sabe”; “óbito é sempre crítico”. 
É sempre uma situação muito dramática, né? Pra equipe, pra todo mundo, pra família, né? Pra nós, os profissionais, que vamos fazer as intervenções, é sempre um momento crítico. (Psicóloga 1)

Identificamos quatro principais desafios enfrentados pelas participantes na realização das ações de cuidado durante todo o processo de internação das mulheres com diagnóstico de óbito fetal. Esses desafios fazem com que elas assumam posições na relação com essas mulheres muito diversas das que assumem no cotidiano da maternidade e, assim, desenvolvam estratégias de cuidado específicas para esses casos. Em relação ao diagnóstico, o principal desafio é informar a morte do bebê sem saber explicar as causas. Isso porque nos casos de óbito fetal há sempre muitos fatores envolvidos, o que demanda uma investigação mais ampla, impossível de ser realizada no momento do diagnóstico. Nesse contexto, uma das estratégias que as profissionais de saúde disseram adotar para lidar com a situação é contar que não sabem as causas e buscar minimizar a suposta culpa da mãe:

Então, eu acho muito difícil você esperar, né? Esse bebê,e, de repente, você ter essa notícia de que houve o óbito fetal. (Assistente social)

'Mãezinha, seu bebezinho tá morto dentro da barriga. A gente não sabe o que aconteceu'. Geralmente a gente tenta tirar a culpa da mãe - que ela sempre acha que ela tem culpa em alguma coisa, entendeu? E que vai ter que ficar internada pra gente fazer a resolução do caso. (Médica)

As dificuldades de profissionais de saúde em comunicar os óbitos de bebês também são observadas nas pesquisas de Lemos e Cunha (2015), Amthauer (2017) e Barlem et al. (2014). Nesse sentido, parece-nos fundamental preparar as/os profissionais para esse tipo de conversa, especialmente no contexto hospitalar.

Outro desafio apontado pelas profissionais que atuam diretamente na assistência à mulher durante o trabalho de parto referiu-se ao momento de explicar as razões pelas quais o parto normal é o mais indicado para os casos de OFIU, quais sejam, a redução do risco de comprometimento da saúde reprodutiva e dos riscos cirúrgicos associados - infecções, hemorragias, restrição na mobilidade e autonomia para o autocuidado, entre outros (Buinoiu et al., 2017). Para enfrentar esse desafio as profissionais relataram que assumem uma postura didática, utilizando como principal argumento a importância de preservar o corpo das mulheres:

A gente explica, né? Que, no caso, o bebezinho não tem mais viabilidade, que a gente tenta preservar o organismo materno pra uma próxima gravidez, né? ... É... é uma grande dificuldade que a gente enfrenta, porque, pra eles [mulheres e familiares], já que não é viável, tem que operar e resolver. Pronto! (Médica)

As dificuldades das profissionais em explicar e serem compreendidas pelas mulheres e famílias sobre as vantagens do parto normal nos casos de óbitos fetais não foram muito exploradas na literatura, mas parece-nos que precisam ser entendidas no contexto cultural brasileiro, no qual circula socialmente uma leitura equivocada de que a cesariana é uma cirurgia simples e sem contraindicações. Essa noção é um desdobramento de uma normalização da cesariana como um modo de nascer que não apresenta grandes riscos e está muito presente na formação de médicos/as obstetras no país (Nakano, Bonan, \& Texeira, 2017). 
Acompanhar o trabalho de parto e o parto das mulheres com diagnóstico de OFIU também se constitui como um desafio para as participantes. As profissionais disseram que o trabalho de parto é mais lento, além de mais difícil, porque as mulheres e a equipe não têm expectativas em relação aos bebês que vão nascer.

A condução do trabalho de parto é totalmente passiva. No caso do óbito fetal, a gente não interfere, ... não faz nenhuma ação que não seja farmacológico. $\mathrm{O}$ banho, essas coisas, a gente oferece. Mas a gente não... tô falando por mim, eu nunca ofereci: 'Ah, vamos ficar na bola, no cavalinho!' ... tem alguns métodos mais sensiveis, né? É aplicado a dolantina, então fica mais fácil ... a gente faz o que está nas nossas condições de fazer mesmo: um Buscopan, essas coisas para dor. Mas não mais que isso. (Enfermeira obstétrica)

O óbito fetal parece colocar a equipe que acompanha o trabalho de parto e parto diante do desafio de lidar com uma mulher que está sofrendo não somente as dores fisiológicas do parto, mas as dores psíquicas ocasionadas pela morte do bebê. Adotar o uso de medicamentos é mais fácil, já que isso não demanda uma interação próxima e é o único recurso que elas sabem usar para amenizar a dor das mulheres. Montero et al. (2011), em seu estudo sobre as experiências de profissionais de saúde sobre a perda perinatal, apontam que muitas vezes as profissionais abandonam a dimensão relacional do cuidado em saúde, assumindo um distanciamento das mulheres através do investimento apenas em procedimentos técnicos.

Outro desafio relatado pelas participantes foi que, após o parto, não há um consenso entre as profissionais em relação ao tempo que os bebês devem permanecer no centro obstétrico junto com as mães. Algumas profissionais relataram achar importante que as mulheres tenham tempo para ver e pegar os seus bebês, já que elas podem não ter outra oportunidade de ficar com eles. No hospital, porém, não há um protocolo para esses casos e algumas profissionais têm pressa de retirar os bebês, a fim de dar continuidade aos procedimentos burocráticos e enviá-los para o necrotério. Com isso, reduzem o tempo de contato entre as mulheres e seus bebês:

O pessoal às vezes tem mania de: já tirou o bebê e já vai fazer papelada... (Enfermeira obstétrica).

Esse modo de lidar com os bebês mortos, querendo retirá-los da cena o mais rápido possível, encontra ressonância numa explicação de Butler (2004), segundo a qual o temor das pessoas em lidar com o luto e com a dor da perda pode levar a uma tentativa de resolvê-lo rapidamente, banindo-o para tentar restaurar a ordem anterior. No caso dos profissionais de saúde, Lemos e Cunha (2015) afirmam que essa rapidez em retirar o bebê da cena do parto é uma tentativa de suprimir o sofrimento e o desconfor to das mães e deles mesmos.

É interessante observar que as relações de cuidado em saúde são mediadas pelos padrões de gênero socialmente construídos, e que têm um papel importante nos posicionamentos que as/os profissionais assumem diante dos casos de óbito fetal.

O enfermeiro da clínica médica tem uma perspectiva singular acerca do sofrimento associado ao OFIU: 
Eu não me lembro de nenhum caso em específico ... Então, sempre que tem essas coisas, assim, na semana, de vez em quando, a gente conversa, tá sempre discutindo. Aí, quando vêm outros óbitos, a gente já criou aquela carapuça e não sente tanto. (Enfermeiro)

Alguns fatores parecem contribuir para esse posicionamento do enfermeiro diante dos óbitos fetais. Ele recebe a mulher no seu setor somente após o parto, portanto, não vivencia os desafios associados ao trabalho de parto e parto; não deseja falar de seus sentimentos; reconhece que nesses casos o sofrimento existe, mas que está protegido porque "já criou uma carapuça”. Nesse sentido, é importante lembrar que esse profissional foi o único homem entrevistado nesta pesquisa e que na cultura patriarcal em que vivemos nem sempre é fácil para os homens falarem de suas emoções.

Já para as profissionais, o fato de serem mulheres e mães amplia o sofrimento:

Ah... eu sou mãe, né? Então é tão difícil, né? Porque, na verdade, você às vezes acaba assim... é... você não está no lugar da pessoa, mas você sente, né? ... Então... eu atendo, mas não é um caso assim... é... que você fala assim: Ah, é como se fosse atender qualquer outro caso'. Não é não! (Assistente social)

Sempre é triste, né? A gente sempre fica comovido. É que com o tempo você aprende a lidar com essa situação, são mais de 25 anos, né? Então você já tem uma postura. Mas sempre você vai pensar: 'E se fosse comigo?' É muito triste! (Médica)

As profissionais se identificam com as mulheres atendidas no contexto hospitalar e sentem-se afetadas pela dor delas. Costa-Junior, Couto e Maia (2016, p. 112), em pesquisa sobre as concepções de profissionais acerca de gênero e cuidado em saúde, afirmam que as interações entre profissionais e usuárias/os no contex to dos serviços são influenciadas pelos papéis de gênero. As/os profissionais entrevistadas/os por eles também se referem a processos de identificação na realização do trabalho em saúde, como, por exemplo: "O fato de paciente e profissional serem do mesmo gênero poderia minimizar a vergonha ou o pudor sentido por ambos em procedimentos invasivos".

A influência das relações de gênero no cuidado em saúde precisa ser mais bem estudada, especialmente no campo da obstetrícia, majoritariamente formado por profissionais mulheres cuidando de outras mulheres, cujas expectativas são forjadas pela cultura em relação à maternidade, ao corpo e aos comportamentos femininos.

Fica evidente na leitura desse repertório que para as/os participantes da presente pesquisa a vida dos bebês tem valor e isso faz com que sofram, se identifiquem com o luto das mulheres e percebam esse cenário como desafiador. Porém na maioria das vezes se posicionam de modo distante das mulheres e suas famílias, desejando sair da situação o mais rápido possível. Esses posicionamentos estão intimamente associados ao modo como a nossa sociedade trata a morte: um tabu, um evento antinatural, que não faz parte do cotidiano e que, por isso, pode ser controlado pelos profissionais de saúde (Praxedes, Araújo, \& Nascimento, 2018; Veras \& Soares, 2016 ). 


\section{A formação para lidar com os casos de óbito fetal}

Nesse repertório, todas/os as/os profissionais entrevistadas/os, à exceção da enfermeira obstétrica, relataram pouca ou nenhuma formação específica para lidar com OFIU. As principais expressões foram: "nunca se falou sobre isso"; "não, especificamente, não"; "eu me assustei muito, porque eu não conhecia"; "a gente teve alguma aula"; "não tive formação"; "algo genérico na formação",

Os estudos que investigam a formação de profissionais de saúde em relação à morte apontam que lidar com ela no cotidiano das ações em saúde demanda recursos e estratégias para os quais as/os profissionais não foram preparados (Araújo \& Nascimento, 2018; Bandeira \& Bisogno, 2011; Ellis et al., 2016; Lima \& Andrade, 2017; Praxedes, Hermes, \& Lamarca, 2013).

A médica, que atua nessa área há 27 anos, lembrou ter discutido óbitos fetais em espaços de formação em apenas dois momentos: um durante a residência médica e outro no curso de Suporte Avançado de Vida em Obstetrícia (ALSO). Ela conta:

Só no ALSO; na formação não. Minto, no Cachoeirinha [hospital paulistano], na residência, a gente teve alguma aula. Eles falaram que nos Estados Unidos a pessoa incentiva a mãe até a fotografar o bebêe [morto] pra ter uma recordação. ... Porque depois passa e ela não quis ver; e ela fica imaginando como era a carinha, como era isso, como era aquilo, e a coisa se perde, entendeu? A aula que eu tive no ALSO, faz tempinho, mas é bem legal. Eles passam um vídeo. (Médica)

Vale ressaltar que essas discussões só ocorreram no momento de uma capacitação profissional em especialidade com um enfoque nas emergências obstétricas.

Uma dimensão muito presente nos estudos sobre a relação dos médicos com a morte diz respeito a frustrações e fracassos diante dela. Muitos se questionam se não poderiam ter feito alguma coisa a mais para evitá-la. Trata-se de formação pautada numa noção, compartilhada em nossa sociedade, de que a morte é algo sempre ruim, um evento que deve ser combatido e dominado, sendo tarefa dos profissionais de saúde vencê-la sempre. E, quando isso não acontece, resta a sensação de derrota (Hoffman, 1993; Mello \& Silva, 2012).

Nos cursos de graduação de enfermagem e de formação de técnicos, muitas vezes, os temas relativos à morte e ao luto são abordados de modo superficial, ou não são abordados. O enfermeiro recorda-se de ter discutido bem pouco os óbitos fetais durante o processo de graduação:

Então, na parte de... no estágio de obstetrícia que a gente fez foi falado um pouquinho sobre óbito fetal para a gente, e também um pouquinho na teoria, né Materno-infantil geral, que a gente estuda. (Enfermeiro)

A enfermeira obstétrica relatou que estudou a dimensão técnica relativa aos abortamentos e aos óbitos fetais e a importância de reconhecer o luto das mulheres e de acolher a mulher, durante o curso de especialização em obstetrícia:

Sim, foi abordado na especialização ... As instruções tanto do abortamento como no caso de óbito fetal, mais a questão de acolhimento desta mulher, foi abordado muito sobre isso... Enfim, a gente fez bastante estudo sobre isso, conversamos muito. (Enfermeira Obstétrica) 
É interessante observar que ela foi uma exceção: da equipe de enfermagem, somente ela disse ter participado de discussões aprofundadas sobre os óbitos fetais e que isso ocorreu no processo de especialização, provavelmente porque ela seria uma das responsáveis diretas por assistir e cuidar desses partos. Assim como a médica, no caso da enfermeira obstétrica esse tema somente foi abordado quando elas já estavam se especializando para atuar no campo da obstetrícia, e não nos cursos de graduação.

Das quatro auxiliares de enfermagem entrevistadas, três disseram que no curso de formação nunca discutiram essa questão, tendo entrado em contato com essa realidade pela primeira vez já na prática hospitalar:

Nunca! Não, nunca tive. Na minha época de formação, nunca se falou sobre isso. Assim, nunca peguei casos no estágio também dessa forma. Tanto é que a primeira vez que eu peguei aqui [no hospital], eu me assustei muito, porque eu não conhecia. Me assusteibastante dever umóbito fetal, deverum aborto, [que] tambémnunca tinha visto. Pra mim foi casos novos assim. (Auxiliar 1)

Uma delas recordou-se de ter tido uma aula em que o tema foi abordado de modo superficial:

Não, especificamente não. ... aula, mas assim, algo muito sucinto, que uma aula muito breve só pra se ter ideia mesmo; não profundidade sobre o tema! (Auxiliar 4)

As auxiliares de enfermagem não foram preparadas para lidar com os casos de OFIU nos cursos que realizaram e não tiveram nenhum tipo de treinamento ao serem admitidas no hospital. Vale lembrar que são elas que têm contato direto com as mulheres em diversos momentos durante a internação e são as responsáveis pela preparação dos corpos dos bebês e o seu encaminhamento para o necrotério. Hermes e Lamarca (2013) destacam que a categoria da enfermagem é a mais afetada emocionalmente nas situações de morte, já que vivencia cuidados mais constantes e próximos aos usuários dos serviços de saúde e suas famílias, testemunhando seus medos e suas angústias.

Bandeira e Bisogno (2011), discutindo a abordagem acerca da morte nos cursos de graduação de enfermagem, demonstraram que trabalhar essa temática, do ponto de vista psicológico e afetivo, é desafiador para o corpo docente. Praxedes, Araújo e Nascimento (2018, p. 375) afirmam que o preparo na graduação nos cursos da saúde, "em especial os de enfermagem, é pautado em procedimentos extremamente técnicos. Onde a reflexão por parte dos alunos em relação à morte/morrer não é instigada e encorajada na academia”.

A abordagem da morte na formação das equipes de enfermagem e médica tem sido bastante discutida na literatura e está muito associada ao fato de que, no contex to hospitalar, são esses profisisonais que vão lidar diretamente com as pessoas internadas e seus familiares, executando procedimentos e conversando sobre diagnósticos e prognósticos. Mas, nesse mesmo cenário, outros profissionais da equipe multiprofissional também participam dos atendimentos aos casos de óbito fetal. Como vimos nesta pesquisa, as psicólogas e as assistentes sociais também sofrem e sentem-se despreparadas para lidar com essas questões. 
A assistente social entrevistada disse não lembrar de ter tido qualquer tipo de formação para lidar com os casos de OFIU. De acordo com ela, as intervenções do serviço social são solicitadas quando a família não tem recursos financeiros, prestando também apoio emocional a essas mulheres. As duas psicólogas relataram ter feito a graduação há muito tempo e estudado a morte apenas de modo genérico:

$$
\text { É algo genérico na formação, né? (Psicóloga 1) }
$$

Subtzki, Lomba e Backes (2018), em seu estudo sobre a percepção da equipe multiprofissional acerca da morte de neonatos, apontam que as/os profissionais das diferentes áreas não são preparados para lidar com a morte. Nesse sentido, Kovács (2016) propõe cursos de educação para a morte, tanto para estudantes quanto para profissionais.

Nesse repertório, a maioria das/os profissionais relataram a ausência de discussão e de preparo para lidar com os casos de óbito fetal nos processos de formação nas diferentes áreas da atenção e reconheceram que esse déficit torna o trabalho mais dificil.

\section{Considerações finais}

A pesquisa nos possibilitou identificar e discutir dois repertórios interpretativos nos discursos das/os profissionais de saúde: o sofrimento e os desafios diante dos partos de natimortos e a formação para lidar com os óbitos fetais. Esses dois repertórios precisam ser entendidos no contexto da nossa sociedade, em que a morte é entendida como algo terrível e assustador e sobre a qual as pessoas não querem pensar ou falar. Soma-se a isso a mentalidade biomédica do nosso tempo, que preconiza uma obstinação terapêutica cujo objetivo final é superar a morte a qualquer custo.

Nesse sentido, esperamos que este estudo contribua para fomentar a discussão sobre a morte na formação acadêmica, bem como para o desenvolvimento de ações de educação continuada nos serviços de saúde. Parece-nos fundamental que esses profissionais aprendam a lidar com as emoções mobilizadas pelos OFIU e que possam, de modo empático, desenvolver ações de cuidado voltadas para as mulheres e suas famílias, já que elas precisam de ajuda para parir seus bebês mortos e estão internadas sob seus cuidados.

Assim, apesar de não ser comum pensar na morte em maternidades, centros obstétricos e salas de parto, vez ou outra ela visita também esses lugares. Enquanto estamos vivos, a morte é onipresente; ainda que nos esforcemos para esquecê-la ou façamos todo o possível para preveni-la ou evitá-la, nem sempre é possível. Então, resta-nos olhá-la nos olhos e aprender a (con)viver com ela como parte inerente da vida. 


\section{Referências}

Amthauer, C. (2017). Vivências e impressões de profissionais de saúde acerca de possíveis causas de uma perda fetal. Rev Enferm UFPE on line, 1 1(Supl. 1), 334-340. doi: 10.5205/ reuol.7995-69931-4-SM.1101sup201712

Aragaki, S. S., Lima, M. L. C., Pereira, C. C. P., \& Nascimento, V. L. V. (2014). Entrevistas: negociando sentidos e coproduzindo versões de realidade. In M. Spink, J. Brigagão, V. Nascimento, \& M. Cordeiro (Orgs), A produção de informação na pesquisa social: compartilhando ferramentas (pp. 57-72). Rio de Janeiro: Centro Edelstein de Pesquisas Sociais.

Ariès, P. (1981). História social da criança e da família. Rio de Janeiro: LTC.

Bandeira, D. \& Bisogno, S. B. C. (2011). A abordagem da morte e morrer na graduação em enfermagem. Um relato de experiência. Revista Contexto E̊ Saúde, 11(21), 11-15.

Barbeiro, F. M. S., Fonseca, S. C., Tauffer, M. G., Ferreira, M. S. S., Silva, F. P., Ventura, P. M., \& Quadros, J. I. (2015). Fetal deaths in Brazil: a systematic review. Rev Saúde Pública, 49, 22. doi:10.1590/So034-8910.2015049005568

Barlem, E. L. D., Freitas, B. H., Barlem, J. G. T., Ramos, A. M., Oliveira, A. C. C., \& Piexak, D. R. (2014). Communication of difficult news in a neonatal intensive care unit. Rev enferm UFPE on line, 8(7),1853-1859. doi: 10.5205/reuol.5963-51246-1RV.0807201404

Buinoiu, N. F., Stoica, S. I., Mat, C., Panaitescu, A., Peltecu, G., \& Gica, N. (2017). Mode of Delivery in Stillbirth. Maedica, 12(2), 101-105.

Butler, J. (2004). Precarious life: the powers of mourning and violence. London; New York: Verso.

Butler, J. (2016). Quadros de guerra: quando a vida é passivel de luto? Rio de Janeiro: Civilização Brasileira.

Costa-Júnior, F. M., Couto, M. T., \& Maia, A. C. B. (2016). Gênero e cuidados em saúde: Concepções de profissionais que atuam no contexto ambulatorial e hospitalar. Sexualidad, Salud y Sociedad, 23, 97-117. doi: https://doi.org/10.1590/1984-6487.sess.2016.23.04.a

Ellis, A., Chebsey, C., Storey, C., Bradley, S., Jackson, S., Flenady, V., Heazell, A., \& Siassakos, D. (2016). Systematic review to understand and improve care after stillbirth: a review of parents' and healthcare professionals' experiences. BMC Pregnancy Childbirth,16, 16. doi:10.1186/s12884-016-0806-2

Hermes, H. R. \& Lamarca, I. C. A. (2013). Cuidados paliativos: uma abordagem a partir das categorias profissionais de saúde. Ciência छ̊ Saúde Coletiva, 18(9), 2577-2588. doi: https://doi.org/10.1590/S1413-81232013000900012

Hoffmann L. (1993). A morte na infância e sua representação para o médico: reflexões sobre a prática pediátrica em diferentes contextos. Cad Saúde Pública, 9(3), 364-374.

Homer, C. S. E. \& Hoope-Bender, P. T. (2016). Supporting women, families, and care providers after stillbiths. The Lancet, 387(10018), 516-517. doi: https://doi.org/10.1016/ $\underline{\text { So } 140-6736(15) 01278-7}$ 
Kelley, M. C. \& Trinidad, S. B. (2012). Silent loss and the clinical encounter: Parents' and physicians' experiences of stillbirth-a qualitative analysis. BMC pregnancy and childbirth, 12, 137. doi: https://doi.org/10.1186/1471-2393-12-137

Kingdon C., O'Donnell E., Givens, J., \& Turner, M. (2015). The Role of Healthcare Professionals in Encouraging Parents to See and Hold Their Stillborn Baby: A Meta-Synthesis of Qualitative Studies. PLoS One,1O(7). e0130059. doi:10.1371/journal.pone.0130059

Kovács, M. J. (2016). Curso Psicologia da Morte: Educação para a morte em ação. Boletim - Academia Paulista de Psicologia, 36(91), 400-417. Recuperado de http://pepsic.bvsalud. org $/$ scielo.php? script $=$ sci arttext\&pid $=$ S1415-711X2016000200010\&lng $=$ pt\&tlng $=$ pt.

Lawn, J. E., Blencowe, H., Waiswa, P., Amouzou, A., Mathers, C., Hogan, D., ...\& Cousens S. (2016). Stillbirths: rates, risk factors, and acceleration towards 2030. The Lancet, 387 (10028), 587-603. doi: https://doi.org/10.1016/So140-6736(15)00837-5

Lemos, L. F. S. \& Cunha, A. C. B. (2015). Morte na maternidade: como profissionais de saúde lidam com a perda. Psicologia em estudo, 20(1), 13-22. doi: https://doi.org/10.4025/ psicolestud.v20i1.23885

Lima, M. J. V. \& Andrade, N. M. (2017). A atuação do profissional de saúde residente em contato com a morte e o morrer. Saúde Soc. São Paulo, 26(4), 958-972. doi:10.1590/ So 104-12902017163041

Mello, A. A. M. \& Silva, L. C. (2012). A estranheza do médico frente à morte: lidando com a angústia da condição humana. Revista da Abordagem Gestáltica, 18(1), 52-60. Recuperado de http://pepsic.bvsalud.org/scielo.php?script=sci arttext\&pid=S1809$\underline{-68672012000100008 \& \operatorname{lng}=p t \& t \operatorname{lng}=p t}$.

Mello, R. P., Silva, A. A., Lima, M. L. C., \& Di Paolo, A. F. (2007). Construcionismo, práticas discursivas e possibilidades de pesquisa em psicologia social. Psicol.Eं Soc., 19(3), 26-32. doi: http://dx.doi.org/10.1590/S0102-71822007000300005

Montero, S. M. P., Sánchez, M. R., Montoro, A. H., Crespo, M. L., Jaén, A. G. V., \& Tirado, M. B. R. (2011). A experiência da perda perinatal a partir da perspectiva dos profissionais de saúde. Rev. Latino-Am. Enfermagem, 19(6). Recuperado de https://www. scielo.br/pdf/rlae/v19n6/pt 18.pdf

Nakano, A.R., Bonan, C., \& Teixeira, L. A. (2017). O trabalho de parto do obstetra: estilo de pensamento e normalização do "parto cesáreo" entre obstetras. Physis: Revista de Saúde Coletiva, 27(3), 415-432. doi: https://dx.doi.org/10.1590/s0103-73312017000300003

Pancino, C. \& Silveria, L. (2010). "Pequeno demais, pouco demais". A criança e a morte na Idade Moderna. Cadernos de História da Ciência, 6(1). Recuperado de http://periodicos. ses.sp.bvs.br/scielo.php? script $=$ sci arttext\&pid $=$ S 1809-76342010000100010\&lng $=$ pt\&n $\underline{\mathrm{rm}=\mathrm{iso}}$.

Potter, J. \& Wetherell, M. (1987). Discourse and social psychology. London: Sage Publications.

Praxedes, A. M., Araújo, J. L., \& Nascimento, E. G. C. (2018). A morte e o morrer no processo de formação do enfermeiro. Psic., Saúde Eீ Doenças, 19(2), 369-376. doi: http:// dx.doi.org/10.15309/18psd 190216 
Spink, M. J. P. (2010). Psicologia Social e Saúde: trabalhando com a complexidade. Quaderns de Psicología, 12(1),41-56.

Spink, M. J. P. \& Medrado, B. (1999). Produção de sentidos no cotidiano: uma abordagem teórico-metodológica para análise das práticas discursivas. In M. Spink (Org.), Práticas discursivas e produção de sentidos no cotidiano: aproximações teóricas e metodológicas (pp. 41-61). São Paulo: Cortez.

Subutzki, L. S., Lomba, M. L., \& Backes, D. S. (2018). Morte de neonatos: percepção da equipe multiprofissional à luz da complexidade. Avances en Enfermería, 36(1), 69-78. doi: https://dx.doi.org/10.15446/av.enferm.v36n1.65229

The Lancet (January, 2016). Ending preventable stillbirths: An Executive Summary for The Lancet's Series. The Lancet. https://www.thelancet.com/pb/assets/raw/Lancet/stories/ series/stillbirths2016-exec-summ.pdf

Hochberg, T. (2011). Moments held- photographing perinatal loss. The Lancet, 377, 13101311. doi: https:// doi.org/10.1016/So140-6736(11)60528-X

Veras, L. \& Soares, J. C. (2016). Aqui se jaz, aqui se paga: a mercantilização da morte. Psicologia \& Sociedade, 28(2), 226-236.doi: $\underline{\text { https://doi.org/10.1590/1807-03102016v28n2p226 }}$

\section{JACQUELINE ISAAC MACHADO BRIGAGÃO \\ https://orcid.org/0000-0002-5566-8839}

Docente do Curso de Obstetricia da Escola de Artes Ciências e Humanidades da Universidade de São Paulo. Orientadora do Mestrado em Gestão de Politicas Públicas (EACH/USP) e do Programa de Pós Graduação em Psicologia da Universidade Federal do Pará.

Endereço institucional: Rua Arlindo Béttio, 1000 - Ermelino Matarazzo, São Paulo - SP, Cep 03828-000.

E-mail: jac@usp.br

\section{ROSELANE GONÇALVES}

https://orcid.org/0000-0003-1861-0985

Docente do Curso de Obstetricia da Escola de Artes Ciências e Humanidades da Universidade de São Paulo

E-mail: roselane@usp.br

\section{BRUNA MARTINS CARDOSO DA SILVA}

https://orcid.org/0000-0002-6720-8901

Obstetriz. Mestranda na Faculdade de Saúde Pública da Universidade de São Paulo.

E-mail: martins.bruna2010@hotmail.com 


\begin{tabular}{|c|c|}
\hline Histórico & $\begin{array}{l}\text { Submissão: 27/03/2020 } \\
\text { Revisão: 09/07/2020 } \\
\text { Aceite: 17/07/2020 }\end{array}$ \\
\hline $\begin{array}{l}\text { Contribuição } \\
\text { dos autores }\end{array}$ & $\begin{array}{l}\text { Concepção: J.I.M.B., R.G. } \\
\text { Coleta de dados: B.M.C.S., J.I.M.B., R.G. } \\
\text { Análise de dados: B.M.C.S., J.I.M.B., R.G. } \\
\text { Elaboração do manuscrito: J.I.M.B., R.G., B.M.C.S. } \\
\text { Revisões críticas de conteúdo intelectual importante: } \\
\text { J.I.M.B., R.G., B.M.C.S. } \\
\text { Aprovação final do manuscrito: J.I.M.B., R.G., B.M.C.S. }\end{array}$ \\
\hline Financiamento & Não se aplica. \\
\hline
\end{tabular}

